\title{
Irritant-induced Asthma Caused by Aerotoxic Syndrome
}

\author{
Jorge Roig ${ }^{1}\left[\right.$ Christian Domingo ${ }^{2,3} \cdot$ Jonathan Burdon $^{4} \cdot$ Susan Michaelis ${ }^{5}$
}

Received: 3 September 2020 / Accepted: 20 February 2021 / Published online: 15 March 2021

(c) The Author(s), under exclusive licence to Springer Science+Business Media, LLC, part of Springer Nature 2021

\begin{abstract}
Purpose Case series on respiratory features of Aerotoxic Syndrome (AS). The term AS has been coined to describe the spectrum of clinical manifestations after aircraft fume events. Among these manifestations, neurological and respiratory symptoms are the most frequently reported complaints.

Methods Three cases of AS with relevant respiratory features are presented.

Results Cough and shortness of breath for 6 to 12 months were the predominant symptoms in the first two cases. The first case also developed neurological symptoms affecting his central nervous system. In the third case, the patient complained for nine years about an unbearable cough triggered by odors, smells, and a variety of indoor and outdoor irritants, among other symptoms of multiple chemical sensitivity. In all three cases, the respiratory symptoms resolved after appropriate treatment. Conclusion Our report aims at raising awareness on AS and calls for actions to improve the management of patients suffering from this syndrome.
\end{abstract}

Keywords Respiratory symptoms $\cdot$ Fumes $\cdot$ Cough $\cdot$ Aerotoxic syndrome $\cdot$ Asthma $\cdot$ Multiple chemical sensitivity

\section{Introduction}

Cabin and flight deck ventilation in most aircraft use outside air mixed with air recirculated from the cabin. This unfiltered outside air comes from the propulsion engine compressors and is commonly known as bleed air. Jet engine oils may leak into the breathing air because seals used in bleed air systems do not completely prevent low levels of contamination from reaching the cabin air in normal flights [1-5]. This phenomenon is known as aircraft fume events. There is variability in the reported incidence of smoke, oil

Jorge Roig

jroig@separ.es

1 Department of Pulmonary Medicine, Clínica Creu Blanca, Barcelona, Spain

2 Department of Pulmonary Medicine, Corporació Sanitària Parc Taulí, Sabadell, Spain

3 Department of Medicine, Autonomous University of Barcelona, Barcelona, Spain

4 Consultant Respiratory Physician, St Vincent's Hospital Melbourne, Fitzroy, VIC, Australia

5 Occupational and Environmental Health Research Group, School of Health Sciences, University of Stirling, Stirling, UK smell, and onboard fume events [3, 4]. In the USA alone, an average of at least two to three contaminated bleed air events have been estimated to occur every day [6]. However, these remain underreported $[6,7]$.

The term aerotoxic syndrome (AS) has been coined to describe the spectrum of clinical features exhibited after aircraft fume events exposure. AS encompasses a constellation of symptoms and individual susceptibility and variation in symptoms are considerable. Of note, the complete list of symptoms and clinical findings are not necessarily found in all any individual cases. A study that reported extensive findings from two different cohorts showed that there may be acute and chronic patterns of adverse effects, affecting the central nervous system (CNS) and peripheral nervous system (PNS) (motor, sensory, and autonomic nervous systems involvement), the respiratory and the gastrointestinal tract, and the cardiovascular system. The symptoms of AS include neurobehavioural affectation (effects on the neurological and cognitive systems); nausea, digestive problems, cramps, nasal or throat irritation, cough, wheezing, variable heart rate and blood pressure, joint or muscle pain, performance decrease, fatigue, and sensitive skin to irritants (chemical sensitivity) [1]. According to previous reports, the respiratory symptoms after fume events exposure rank only second to neurological symptoms in their frequency 
[1, 3-5]. Symptoms, signs, objective measurements, and diagnoses are usually recorded by medical personnel and by the affected persons themselves. However, no consistency in diagnosis nor in record keeping have been reached so far $[8,9]$.

This could be due to the controversy surrounding AS. Over the years, there has been a lack of timely and systematic investigation of fume events, which has propelled the debate around the contamination sources and components, toxicity, consistency of signs and symptoms, and lack of causal mechanism [1-9]. Besides, potential contaminants at the time of exposure have not been properly identified. These inadequacies in information have hindered, not only the assessment of measured abnormalities and their relationship to clinical symptoms, but also the development and implementation of preventive and therapeutic strategies.

Herein, we report three cases of flight crew presenting symptoms that corresponded to those described for AS.

\section{Summary of Cases}

Case 1. A 47-year-old man, international airline pilot, experienced four episodes of cabin air fume events over two years during flights. Two of them were oil smell episodes and the other two were visible smoke events of unknown origin. None were sufficiently serious to prompt an emergency landing. During the last smoke event, the pilot developed a mild cough and shortness of breath that persisted for several weeks. He had ceased a mild smoking habit 17 years before this event. His medical and surgical histories were unremarkable. Previous spirometry on regular, periodic checkups had always been normal. The patient was evaluated at our Pulmonary Department one month after the beginning of the fourth episode. He presented with moderate wheezing, severe cough productive of a tiny amount of whitish sputum, and moderate dyspnea. He reported some difficulties with immediate memory recall and, occasionally, with his fluency of speech. In addition, he noticed some pain radiating down his arms and slight numbness and tingling in the fingers. Cardiopulmonary auscultation revealed bilateral wheezing. Physical examination of the nervous system and brain CT scan were normal. His blood pressure was normal, and he was afebrile. The results of a chest X-ray and a thoracic CT scan did not show any relevant abnormalities and his sputum microbiology was negative. A PCR test (Film Array Respiratory Panel 2 plus) of nasopharyngeal secretions was negative for the following microorganisms: adenovirus, influenza A and B viruses, parainfluenza, respiratory syncytial, rhinovirus/enterovirus, Chlamydia pneumoniae, Mycoplasma pneumoniae, Bordetella pertussis, metapneumovirus, and coronavirus. ERS, CRP, and total white cell count were slightly above the upper limit. The results of routine biochemistry were normal and serological tests for HIV were negative. The spirometry test showed a moderate airway obstruction with a strongly positive bronchodilator test. A 20\% increase of FEV1 was shown after inhalation of the short-acting bronchodilator agent albuterol. The results of pulmonary function studies performed on the patient are summarized in Table 1. Reference values were those of the European Respiratory Society (ERS) / 2012 Global Lung Initiative (GLI) for the adult population [10]. His diffusion capacity for carbon monoxide $\left(\mathrm{D}_{\mathrm{LCO}}\right)$ was normal.

Based on the clinical history and negative microbiology of the patient, a diagnosis of transient irritant asthma related to AS was achieved. An alternative diagnosis of reactive airways syndrome (RADS) was ruled out because of the lack of a positive methacholine test, always required to establish such diagnosis. He was prescribed oral steroids, leukotriene inhibitors, inhaled long-acting muscarinic agents, and longacting beta-adrenergic agents. Respiratory symptoms progressively subsided during the following six months, but he reported a mild worsening of his neurological symptoms. At that time, extensive blood tests were again normal, including negative immunological studies (ACE, rheumatoid factor, ANA, and ANCA) and MRI examination of head and spine, nerve conduction studies, and EMG were also normal. A blood sample submitted to Duke University showed highly positive results for autoantibodies against myelin basic protein (MBP), neurofilament proteins, microtubule-associated tau proteins, tubulin, and microtubule-associated protein-2 (MAP-2), all biomarkers for neuronal degeneration [11]. Moreover, high levels of autoantibodies against glial fibrillary acidic protein and the glial calcium-binding protein S-100B, both astrocytic markers for brain injury, were also observed. Inhaled therapy was eventually withdrawn after six months of treatment without any relapse on long-term follow-up.

Table 1 Pulmonary function studies in case 1: a patient with RADS related to $\mathrm{AS}$

\begin{tabular}{lll}
\hline Pulmonary function test & Measured & $\%$ Predicted* \\
\hline TLC, $L$ & 7.47 & 91 \\
RV, $L$ & 2.82 & 111 \\
FVC,$L$ & 5.09 & 101 \\
FEV1, $L$ & 2.45 & 63 \\
FEV1/FVC & 48 & 63 \\
$\mathrm{FEF}_{25-75}, L$ & 0.94 & 25 \\
$\mathrm{D}_{\mathrm{LCO}}, \mathrm{mL} / \mathrm{min} / \mathrm{mm} \mathrm{Hg}$ & 25.8 & 82 \\
\hline
\end{tabular}

$A S$ aerotoxic syndrome, $D_{L C O}$ diffusion capacity for carbon monoxide, $F E F_{25-75}$ forced expiratory flow $25-75 \%, F E V 1$ forced expiratory volume in one second, FEV1/FVC ratio of FEV1 to FVC, $F V C$ forced vital capacity, $R A D S$ reactive airway dysfunction syndrome, $R V$ residual volume, $T L C$ total lung capacity

*Reference values: ERS for adult population (GLI 2012) 
Case 2. A 34-year-old woman, international airline flight attendant, was exposed to a few, repetitive oil smells in the cabin during takeoff and landing for two weeks. She complained of non-specific upper respiratory tract irritation, a mild but progressive dry cough, and skin itching. After a strong smell in the cabin, she developed a skin rash that involved particularly her two ears (Fig. 1a) and trunk (Fig. 1b); her cough worsened, and she began to complain about mild dyspnea. She denied having been bitten by an insect and was not taking any oral medication. A chest X-ray performed at the onset of the symptoms was unremarkable. Her past medical history was unremarkable. No eosinophilia was detected. The rash subsided after a course of oral steroid therapy, but her moderate shortness of breath and dry cough persisted. The patient was evaluated at our Pulmonary Department two months after the beginning of the first episode. The results of her physical examination were unremarkable. Baseline spirometry values was normal, but bronchodilator testing assessed by inhalation of albuterol showed an increase of $11 \%$ in FEV1. $\mathrm{D}_{\mathrm{LCO}}$ and thoracic CT scan were normal. Thus, a diagnosis of transient irritant asthma related to AS was achieved. The patient was treated with inhaled therapy (fluticasone furoate and vilanterol). The respiratory symptoms progressively subsided. Inhaled therapy was withdrawn after six months of treatment without any relapse on long-term follow-up.

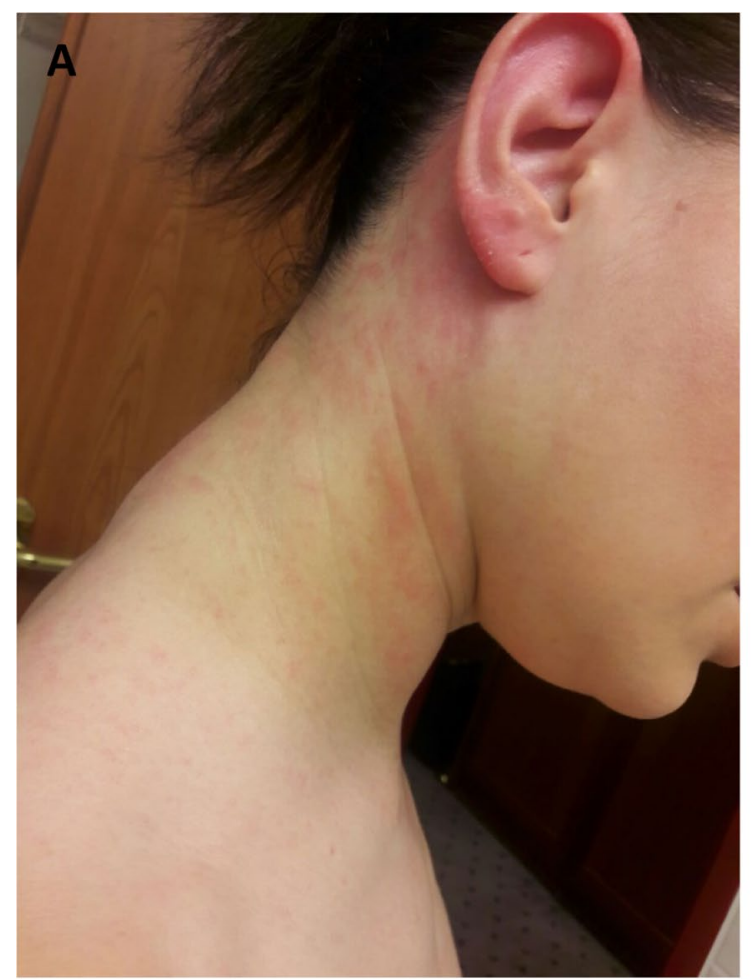

Case 3. A 56-year-old woman, international airline pilot, presented with symptoms of a long-term, unbearable, dry cough and symptoms of an upper respiratory tract irritation. The origin was related to exposure to a variety of environmental substances or smells. Almost any environmental cause triggered coughing. She had to stop wearing perfume and using aerosols. Other symptoms included overwhelming fatigue, mild cognitive impairment, recurrent headaches, dry eyes, relapsing inflammation of eyelids, pain in her legs and shoulders, generalized muscle weakness, dizziness, and tingling in her fingertips. A few years after the onset of her symptoms she had been forced to stop flying. The psychiatric evaluation had never revealed any relevant abnormality except for some anxiety related to her unpleasant health status. The onset of these symptoms, soon after a fume event, occurred nine years before the evaluation at our Pulmonary Department. At that time, four passengers of the same flight also required medical assistance after showing nausea and shortness of breath. Before that episode, our patient had never complained about any symptoms that could have been suggestive of bronchial hyperresponsiveness. Blood tests and neurological evaluation had been normal, except for subtle findings on a brain scan of a low pulsatility of sylvian and thalamic arteries. A blood sample submitted to Duke University showed a highly significant increase in myelin-associated glycoprotein [11]. The results of all her

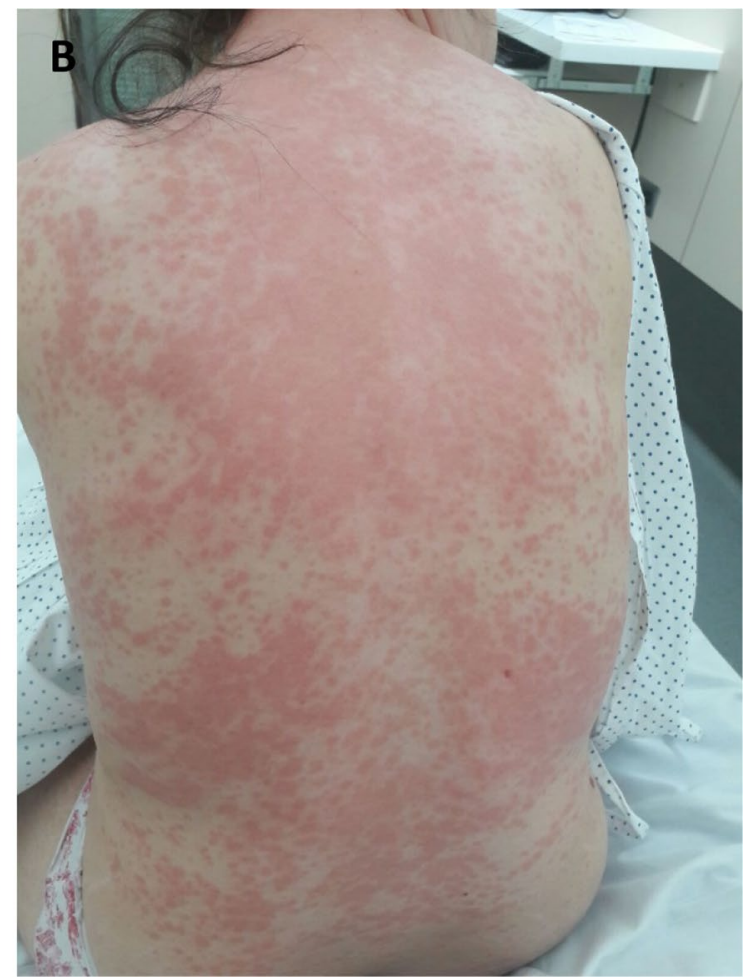

Fig. 1 a, Bilateral erythema and inflammation of ear skin and cartilage (auricular chondritis) after exposure to aircraft fumes. b, Maculo-papular trunk rash after exposure to aircraft fumes 
chest X-ray had always been normal. Her baseline spirometry results were within normal limits, but a positive bronchodilator response of $10 \%$ in FEV1 was observed following inhalation of albuterol. $\mathrm{D}_{\mathrm{LCO}}$ was normal. Interestingly, upon breathing the gas mixture used to perform the diffusion test, a severe cough episode was triggered. A diagnosis of irritant asthma and multiple chemical sensitivity (MCS) related to AS was concluded. The patient was placed on daily inhaled therapy with fluticasone furoate and vilanterol. Her cough improved but non-respiratory symptoms persisted on longterm follow-up.

\section{Discussion}

Our case series was focused on the respiratory symptoms of AS. In the first case, the symptoms, pulmonary evaluation, clinical history, and negative microbiology of the airline pilot supported a diagnosis of transient irritant asthma related to AS. In the second case, the symptoms, unremarkable results of several tests, and positive outcome of a bronchodilator test allowed us to achieve, again, a diagnosis of transient asthma related to AS. Finally, in the third case, the symptoms, clinical history, and the response to a bronchodilator test resulted in a diagnosis of MCS related to AS.

Generally, cough, dyspnea, chest discomfort, and wheezing are the usual respiratory features of AS. In some cases, the duration of symptoms may be just a few days or weeks, but sometimes respiratory complaints may last over many months and even longer. Some of these cases could also be, occasionally, diagnosed as RADS [1]. Previous exposure to an irritating agent, persistent cough and wheezing, absence of previous respiratory complaints, duration of symptoms for at least three months, and documented data to support bronchial hyperresponsiveness many months after fume events are the hallmark of RADS, a likely presentation of AS [12-14]. Since a positive result in the methacholine test is one of the diagnostic criteria of RADS, this diagnosis could not be confirmed in our cases. A word of caution has been suggested since limits between RADS and irritative asthma are sometimes quite difficult to be drawn [14]. The bronchodilator testing for case one fulfilled the classical criteria established by the ATS-ERS statement on spirometry, that is, an increase in FEV1 greater than $12 \%[15,16]$. The results of bronchodilator testing for cases two and three were very close to the stringent limits included in this statement. Other authors have suggested that an increase in FEV1 of more than $8 \%$ could also be considered as positive when spirometry at baseline is within normal limits [17, 18]. A positive bronchodilator response according to ATS/ERS guidelines requiring both $200 \mathrm{ml}$ and $12 \%$ increase in FEV1 or FVC after bronchodilator inhalation could be insensitive in those with high or low FEV1 [19].
Regarding neurological symptoms, the most frequently reported features of AS [1], a diffuse pattern is usually observed. A variety of symptoms involving both CNS and PNS have been reported: headache, impaired consciousness; trouble speaking; balance problems; visual disturbances; lack of coordination; dizziness; drowsiness; and shaking, twitches, tremors, tingling or flushing of extremities; among others. Cognitive and neurobehavioral complaints are also quite common. Usually, the routine neurological examinations are not sensitive enough to detect the underlying abnormalities responsible for mild symptoms. Both MRI examination and nerve conduction studies do not demonstrate any relevant abnormalities in AS cases [1]. However, increased levels of autoantibodies against neuronal and/or glial proteins, as found in our cases 1 and 3 , would be consistent with non-specific chemical-induced nervous system injury [11].

Concerning skin manifestations, dermal folliculitis is the most frequent feature of AS. However, other skin rashes, as found in our second case, have been also reported in AS [20]. They are usually transient but may also be recurring.

Our third case, with distinctive symptoms for many years, fulfilled the criteria of MCS, also known as idiopathic environmental intolerance, another long-term possible respiratory presentation of AS $[1,21]$. This syndrome, also controversial because of the lack of reliable case definitions, is characterized by complains about sensitivity and heterogeneous, non-specific symptoms when exposed to low concentrations of chemicals commonly present in the environment and well tolerated by the general population [22]. Some patients with MCS have also reported intermittent or chronic exposure to low levels of chemicals such as pesticides [23].

With respect to AS, the causative agents are also diverse. Fume events in aircrafts are described in a variety of ways [1]. Most have no visual identifying features, such as mist or smoke. Oil fumes are typically described as smelling like dirty socks/smelly feet, foul, musty or oily odors, while hydraulic fluid is often described as acrid. The dirty socks or smelly feet description, often used, is increasingly understood to be related to the thermal degradation and hydrolysis of the oil base stocks. In most aircraft engine oils, a hazardous substance that can be found is tricresyl phosphate, a compound with proven toxicity [24-27]. Moreover, the high temperatures attained in aircraft jet engines may cause thermal pyrolysis able to produce potentially toxic, still not well defined, chemical substances [25, 28]. Besides, respiratory, and neurological toxicity derived from exposure to nanoparticles released by bleed air systems in the breathing air of commercial aircraft has also been reported [29]. Other contamination sources may include hydraulic fluids or flame retardants emanating from the highly flame-protected environment of airplanes [30]. Minimization of potential contaminating sources and/or improved reduction of pollutants by air 
cleaning should be mandatory to diminish the risk of AS [1-9, 24-26]. An important device for air cleaning in aircraft are HEPA filters, and improving their efficacy would decrease the risk of infection caused by airborne microorganisms such as SARS - CoV 2, A/H1N1 influenza virus, and others [1,31-33]

Nowadays, many clinicians are not aware of the existence of AS; hence, when patients require medical assistance after a fume event, the lack of a good, standardized protocol precludes general recommendations on the immediate identification of the implicated chemical toxins, on the type of pulmonary and neurological studies to perform, and on the therapeutic management of the disease [1]. Urine and blood samples should be obtained without delay after a fume event and strict technical requirements should be mandatory [1]. A standardized protocol to properly approach cases suspected of AS is currently drawn up by a team of international experts on the subject [34]. Besides, since more than two million people fly in commercial aircrafts every day all over the world, there is a need to raise awareness on this entity [1].

However, not all aircrew or passengers are affected by fume events [1]. Probably, individual susceptibility, most likely based on genetic traits such as those related to cytochrome $\mathrm{P}-450$ and paraoxonase-1 (PON-1), play a role in an eventual development of AS after fume events $[35,36]$. In addition, recurrent and cumulative inhalation of tiny concentrations of chemical substances in airplane cabins could explain why some become ill after long-term exposure $[1,7]$. This would have obvious connotations for members of aircrews, maintenance staff, and frequent fliers. Besides, some routine medical treatments and even dietary factors may also interfere with the metabolic activity of cytochrome P-450 or PON-1 [35, 37]. At present, the potential role of underlying diseases in triggering AS is unknown.

In conclusion, our report of three cases of AS aims at raising awareness on this unknown disease, particularly on the respiratory symptoms, and calls for the implementation of standardized protocols to manage AS [1-9, 34]. Further research is warranted to clarify which chemical substances are potentially causative of this syndrome, which populations are more susceptible, and which preventive and therapeutic measures should ideally be implemented [1, 3-9].

Acknowledgements The authors thank Matías Rey-Carrizo, $\mathrm{PhD}$, from BCN Medical Writing for providing editorial support

\section{Declarations}

Conflict of interest Susan Michaelis undertakes limited consultancy work for the Global Cabin Air Quality Executive. Horsham, UK. Email address: susan@susanmichaelis.com. Jorge Roig, Jonathan Burdon, and Christian Domingo declare no conflict of interest.

\section{References}

1. Michaelis S, Burdon J, Howard CV (2017) Aerotoxic syndrome: a new occupational disease? Public Health Panorama (WHO) $3: 141-356$

2. Winder C, Balouet JC (2002) The toxicity of commercial jet oils. Environ Res 89:146-164. https://doi.org/10.1006/enrs. 2002.4346

3. Howard CV, Michaelis S, Watterson A (2017) The aetiology of 'aerotoxic syndrome' - A toxico pathological viewpoint. Open Acc J Toxicol 1:555575. https://doi.org/10.19080/OAJT.2017. 01.555575 .002

4. Harrison V, Mackenzie Ross SJ (2016) An emerging concern: toxic fumes in airplane cabins. Cortex 74:297-302. https://doi. org/10.1016/j.cortex.2015.11.014

5. Hageman G, Pal TM, Nihom J, Mackenzie Ross SJ, van den Berg M (2020) Three patients with probable aerotoxic syndrome. Clin Toxicol (Phila) 58:139-142. https://doi.org/10. 1080/15563650.2019.1616092

6. Shehadi M, Jones B, Hosni M (2016) Characterization of the frequency and nature of bleed air contamination events in commercial aircraft. Indoor Air 26:478-488. https://doi.org/10. 1111/ina.12211

7. Liyasova M, Li B, Schopfer LM, Nachon F, Masson P, Furlong $\mathrm{C}$ et al (2011) Exposure to tri-o-cresyl phosphate detected in jet airplane passengers. Toxicol Appl Pharmacol 256:337-347. https://doi.org/10.1016/j.taap.2011.06.016

8. Schopfer LM, Furlong CE, Lockridge O (2010) Development of diagnostics in the search for an explanation of aerotoxic syndrome. Anal Biochem 404:64-74. https://doi.org/10.1016/j.ab. 2010.04.032

9. Hageman G, Pal TM, Nihom J, Mackenzie Ross SJ, Berg MVD (2019) Aerotoxic syndrome, discussion of possible diagnostic criteria. Clin Toxicol (Phila) 58:414-416. https://doi.org/10. 1080/15563650.2019.1649419

10. Quanjer PH, Stanojevic S, Cole TJ et al (2012) Multi-ethnic reference values for spirometry for the 3-95-yr age range: the global lung function 2012 equations. Eur Respir J 40(6):13241343. https://doi.org/10.1183/09031936.00080312

11. Abou-Donia MB, Abou-Donia MM, ElMasry EM, Monro JA, Mulder MF (2013) Autoantibodies to nervous system-specific proteins are elevated in sera of flight crew members: biomarkers for nervous system injury. J Toxicol Environ Health A 76:363380. https://doi.org/10.1080/15287394.2013.765369

12. Shaffo FC, Grodzki AC, Fryer AD, Lein PJ (2018) Mechanisms of organophosphorus pesticide toxicity in the context of airway hyperreactivity and asthma. Am J Physiol Lung Cell Mol Physiol 2018(315):L485-L501. https://doi.org/10.1152/ajplung. 00211.2018

13. Alberts WM, do Pico GA (1996) Reactive airways dysfunction syndrome. Chest 109:1618-1626. https://doi.org/10.1378/chest. 109.6.1618

14. Lemière C, Boulet LP, Cartier A 2020 Reactive airways dysfunction syndrome and irritant -induced asthma. Section Editor: Barnes PJ (ed) UpToDate Inc, Waltham, MA. https://www.uptod ate.com. Accessed 17 Jan 2021

15. Pellegrino R, Viegi G, Brusasco V, Crapo RO, Burgos F, Casaburi R et al (2005) Interpretative strategies for lung function tests. Eur Respir J 26:948-968. https://doi.org/10.1183/09031 936.05.00035205

16. Graham BL, Steenbruggen I, Miller MR, Barjaktarevic IZ, Cooper BG, Hall GL et al (2019) Standardization of spirometry 2019 update. An official american thoracic society and european respiratory society technical statement. Am J Respir Crit Care Med 200:e70-e88. https://doi.org/10.1164/rccm.201908-1590ST 
17. Kaminsky AD (2019) What is a significant bronchodilator response? Ann Am Thorac Soc 16:1495-1503. https://doi.org/ 10.1513/AnnalsATS.201908-604ED

18. Irwin CG (2020) Pulmonary function testing in asthma. In Barnes PJ (ed). UpToDate Inc, Waltham, MA. https://www.uptodate.com. Accessed 17 Jan 2021

19. Hansen JE, Dilektasli AG, Porszasz J, Stringer WW, Pak Y, Rossiter HB et al (2019) A new bronchodilator response grading strategy identifies distinct patient populations. Ann Am Thorac Soc 16(12):1504-1517. https://doi.org/10.1513/AnnalsATS. 201901-030OC

20. Harper A (2005) A survey of health effects in aircrew exposed to airborne contaminants. J Occup Health Saf Aust N Z 21:433-439

21. Idiopathic environmental intolerances (1999) American Academy of Allergy, Asthma and Immunology (AAAAI) Board of Directors. J Allergy Clin Immunol 103(1 Pt 1):36-40 (PMID: 9893182)

22. Tuuminen T (2018) Multiple chemical sensitivity: review of the state of the art in epidemiology, diagnosis, and future perspectives. J Occup Environ Med 60(8):e429. https://doi.org/10.1097/ JOM.0000000000001369

23. Black DW, Temple S (2020) Idiopathic environmental intolerance (multiple chemical sensitivity). Dimsdale J (ed). UpToDate Inc, Waltham, MA. https://www.uptodate.com. Accessed 17 Jan 2021

24. Furlong CE (2011) Exposure to triaryl phosphates: metabolism and biomarkers of exposure. J Biol Phys Chem. https://doi.org/ 10.4024/28FU11A.jbpc.11.04.10.4024/28FU11A.jbpc.11.04

25. Megson D, Ortiz X, Jobst KJ, Reiner EJ, Mulder MF, Balouet JC (2016) A comparison of fresh and used aircraft oil for the identification of toxic substances linked to aerotoxic syndrome. Chemosphere 158:116-123. https://doi.org/10.1016/j.chemosphere. 2016.05.062

26. Baker PE, Cole TB, Cartwright M, Suzuki SM, Thummel KE, Lin YS et al (2013) Identifying safer anti-wear triaryl phosphate additives for jet engine lubricants. Chem Biol Interact 25(203):257264. https://doi.org/10.1016/j.cbi.2012.10.005

27. Costa LG (2018) Organophosphorus compounds at 80; some old and new issues. Toxicol Sci 162:24-35. https://doi.org/10.1093/ toxsci/kfx266

28. Van Netten C, Leung V (2001) Hydraulic fluids and jet engine oils: pyrolysis and aircraft air quality. Arch Environ Health 56:181-186. https://doi.org/10.1080/00039890109604071

29. Howard CV, Johnson DW, Morton J, Michaelis S, Supplee D, Burdon J (2018) Is a cumulative exposure to a background aerosol of nanoparticles part of the causal mechanism of aerotoxic syndrome? J Nanomedicine Nanosci. https://doi.org/10.29011/ JNAN-139

30. Schindler BK, Weiss T, Schütze A, Koslitz S, Broding HC, Bünger J, Brüning T (2013) Occupational exposure of air crews to tricresyl phosphate isomers and organophosphate flame retardants after fume events. Arch Toxicol 87:645-648. https://doi.org/ 10.1007/s00204-012-0978-0

31. Pombal R, Hosegood I, Powell D (2020) Risk of COVID-19 during air travel. JAMA 324:1798. https://doi.org/10.1001/jama. 2020.19108

32. Baker MG, Thornley CN, Mills C, Roberts S, Perera S, Peters $\mathrm{J}$ et al (2010) Transmission of pandemic A/H1N1 2009 influenza on passenger aircraft: retrospective cohort study. BMJ 21(340):c2424. https://doi.org/10.1136/bmj.c2424

33. Wilson ME (2020) What goes on board aircraft? . Travel Med Infect Dis 33:101572. https://doi.org/10.1016/j.tmaid.2020. 101572

34. Heutelbeck AR, Baur X, Belpoggi F, Budnik T, Burdon J, Gee D, et al (2017) On the need for a standardized human biomonitoring protocol for in-flight incidents (called "fume events") (Abstract). J $\mathrm{H} \& \mathrm{P}$. 2nd International Conference Pollution in living and working environments and health. DiMoPEx Working Groups Meeting; Abstracts Conference Proceedings. S36-S38

35. Reinen J, Nematollahi L, Fidder A, Vermeulen NP, Noort D, Commandeur JN (2015) Characterization of human cytochrome p450s involved in in the bioactivation of tri-ortho-cresyl phosphate (ToCP). Chem Res Toxicol 28:711-721. https://doi.org/10. 1021/tx500490v

36. Costa LG, Giordano G, Cole TB, Marsillach J, Furlong CE (2013) Paraoxonase 1 (PON1) as a genetic determinant of susceptibility to organophosphate toxicity. Toxicology 307:115-122. https://doi. org/10.1016/j.tox.2012.07.011

37. Costa LG, Giordano G, Furlong CE (2011) Pharmacological and dietary modulators of paraoxonase 1 (PON1) activity and expression: the hunt goes on. Biochem Pharmacol 81:337-344. https:// doi.org/10.1016/j.bcp.2010.11.008

Publisher's Note Springer Nature remains neutral with regard to jurisdictional claims in published maps and institutional affiliations. 